\title{
Gaz Kromatografisi/Kütle Spektrometrisi ile Sudaki Pestisit Kalıntılarının Eşzamanlı Olarak Belirlenmesi için Çoklu Kalıntı Metodu Geliştirilmesi
}

\author{
Bahar A. Bayrak ${ }^{1 *}$ \\ ${ }^{1}$ Atatürk Üniversitesi, Mühendislik Fakültesi, Kimya Mühendisliği Bölümü, Erzurum, Türkiye (ORCID: 000000031503 2841)
}

(İlk Geliş Tarihi 12 Temmuz 2018 ve Kabul Tarihi 1 Mart 2019)

(DOI: 10.31590/ejosat.443014)

ATIF/REFERENCE: Bayrak, B. A. (2019). Gaz Kromatografisi/Kütle Spektrometrisi ile Sudaki Pestisit Kalıntılarının Eşzamanlı Olarak Belirlenmesi için Çoklu Kalıntı Metodu Geliştirilmesi. Avrupa Bilim ve Teknoloji Dergisi, (16), 84-91.

Öz

Sıvı-Sıvı ekstraksiyonu (LLE) ve ardından gaz kromatografisi kütle spektrometrisi (GC/MS) ile pestisitlerin tayini için çoklu kalıntı yöntemi geliştirildi.

Yöntem; her bir pestisit için nicel tayin sınırı (LOQ) ve belirtme alt sınırı (LOD), doğrusallık ve doğruluk parametrelerine göre değerlendirildi. GC/MS için, LOD değerleri $1.27 \mu \mathrm{g} / \mathrm{L}$ ile $4.24 \mu \mathrm{g} / \mathrm{L}$ arasında ve LOQ değerleri $4.23 \mu \mathrm{g} / \mathrm{L}$ ile $14.15 \mu \mathrm{g} / \mathrm{L}$ arasında elde edildi. Geri kazanım değeri, yüksek konsantrasyon için \% 96 elde edilirken düşük konsantrasyonlarda \% 92 olarak bulundu. Tekrarlanabilirlik (simazin hariç) 3.81 ila 14.40 arasında değişirken, yeniden üretilebilirlik (RSD\%) 5.81 ila 17.32 arasında değişmiştir.

Anahtar Kelimeler: Pestisitler, Metot validasyonu, GC/MS.

\section{Development of a Multiresidue Methods for The Simultaneous Determination of Pesticide Residues in Water by GC/Mass Spectrometry}

\begin{abstract}
A Multi-residue methods were developed for the determination of pesticides by liquid-liquid extraction (LLE) and followed by gas chromatographymass spectrometry (GC/Mass).

The method was evaluated with respect to the limit of detection and quantification, linearity and accuracy. For GC/MS, LODs were between $1.27 \mu \mathrm{g} / \mathrm{L}$ and $4.24 \mu \mathrm{g} / \mathrm{L}$ and LOQs were between $4.23 \mu \mathrm{g} / \mathrm{L}$ and $14.15 \mu \mathrm{g} / \mathrm{L}$. Recoveries were obtained over $96 \%$ in high concentration and $92 \%$ in low concentration. Repeatabilities were varied from 3.81 to 14.40 (except for simazine) and reproducibilities (RSD\%) were varied from 5.81 to17.32.
\end{abstract}

Keywords: Pesticides, Method validation, GC/MS.

1 Sorumlu Yazar: Atatürk Üniversitesi, Mühendislik Fakültesi, Kimya Mühendisliği Bölümü, Erzurum, Türkiye Tel: 04422314518, Faks:04422314910, ORCID: 000000031503 2841, batabek@atauni.edu.tr 
European Journal of Science and Technology

\section{Giriş}

Pestisitler; kemirgenler, böcekler, mantarlar ve yabancı otlar gibi zararlıları öldürmek veya kontrol etmek için kullanılan kimyasal ya da biyolojik ürünlerdir (Domotorova ve Matisova, 2008). Bu ürünler, zararlıları yok ederken aynı zamanda su ve toprağa karışarak canlılar için ciddi riskler oluşturmaktadır. Pestisitlerin canlı vücuduna zararlı etkileri sonucu, akut anemi, kemik yapısı bozuklukları, teratojenik ve embriyolojik hastalıklar oluşmaktadır. Bunun yanı sıra vücuttaki sinir sistemi, endokrin sistemi gibi sistemlerde doğrudan etkilenmektedir (Castilho vd., 2000). Maruz kalınan doza bağlı olarak ölüme kadar varan sonuçlar görülmektedir. Ayrıca pestisitlerin yarılanma ömürleri uzun olabildiğinden canlı organizmalar üzerinde uzun vadede etkileri devam etmektedir. Bunun sonucu olarak, pestisitlere direnç geliştiren yeni zararlılar ortaya çıkmakta ve bu zararlıların oluşturduğu farklı etkileri yok edebilmek için daha fazla pestisit kullanılması veya yeni tarım ilaçlarının geliştirilmesi söz konusu olmaktadır (Costa vd., 2008). Bu döngü nedeniyle ekosistem içerisinde pestisit kullanımı her geçen gün artmaktadır. Özellikle tarımda yoğun olarak kullanılan pestisitler sulama sonucu yeraltı suları ve yüzey sularına kolayca karışmaktadır (Komatsu ve Vaz, 2004). Pestisitler kendi aralarında organoklorlu ve organofosforlu pestisitler, herbisitler, fungusitler gibi sınıflara ayrılmaktadır. Bunların içerisinde en çok kullanılanı organoklorlu ve organofosforlu pestisitlerdir. Son yıllarda, organofosforlu pestisitlerin bozunma hızları organoklorlu pestisitlere kıyasla daha hızlı olduğundan tarım alanlarında kullanımı yaygınlaşmıştır (Beltran vd., 1998; Driss vd., 1993). Pestisitlerin yoğun bir şekilde kullanılması nedeniyle toprak ve suda kirliliğin sürekli artması, pestisitlerin varlığını tespit etmek için etkili analitik yöntemlerin geliştirilmesine ve bu yöntemlerle kalıntıların düzeyinin sürekli takip edilmesi gerekliliğine yol açmıştır (de Souza Pinheiro ve de Andrade, 2009; Park vd., 2011). Bununla birlikte, yeni geliştirilen yöntemlerin çevreye daha duyarlı, daha hızlı, düşük dedeksiyon limitine sahip ve seçici olması gereklidir.

Pestisitlerin belirlenmesi için genellikle karmaşık kromotografik cihazlar kullanılmaktadır. Ancak sudan pestisiti ayırıp diğer girişim yapabilecek maddeleri uzaklaştırmak ve daha hassas sonuçlar elde edebilmek için öncesinde bir ekstraksiyon işlemine ihtiyaç duyulmaktadır (Beltran vd., 1998). Pestisitlerin ekstrakte edilerek sudan uzaklaştırılması ve daha yoğun hale getirilmesi için; sıvı-sıvı ekstraksiyonu, katı faz ekstraksiyonu, katı fazlı mikro ekstraksiyon, süperkritik sıvı özütleme, matris katı faz dağılımı ve hızlandırılmış çözücü özütleme gibi birkaç önemli teknik vardır (Jin vd., 2012).

Pestisitler çoğunlukla, yüksek performanslı sıvı kromatografisi (HPLC), sıvı kromotografi(LC/MS) veya gaz kromatografisi (GC) gibi farklı kromatografik teknikler yardımıyla tayin edilmektedir(Dorea vd., 1996; Piedra vd., 2000; Rocha vd., 2012).

Gaz kromatografisi, genellikle farklı dedektörler yardımıyla birçok maddenin tespiti için geniş bir kullanım alanına sahiptir. Organofosforlu bileşikleri, gaz kromatografisi/azot fosfor dedektör(GC-NPD) ve gaz kromatografisi/kütle spektrometresi(GC/MS) yardımıyla daha yüksek hassasiyetle tespit etmek mümkündür. Organoklorlu pestisitler, pyrethroidler ve imidazol kompleksleri; gaz kromatografisi/elektron yakalama dedektörü(GC-ECD) ile mükemmel hassasiyette tespit edilmektedir. Organofosforlu ve organoklorlu pestisitler aynı anda gaz kromatografisi/kütle spektrometresi (GC/MS) ile tespit edilebilmektedir (Menezes Filho vd., 2010).

Yeni geliştirilen yöntem; kalıntıların tanımlanmasını ve çok düşük konsantrasyon seviyelerinde dahi miktarın doğru bir şekilde tespitini sağlamalıdır(Vidal vd., 2006). Pestisit kalıntı analiz metodu esas itibarıyla güvenilir, verimli, sağlam ve basit olmalıdır. Metodolojinin geçerliliği, analitik verileri teyit ettiği için son derece önemlidir (Suman ve Singh, 2011).

$\mathrm{Bu}$ çalışmanın amacı, suyu kirleten pestisitleri GC/MS ile belirlemek için basit (etkin, hızlı) ve verimli çoklu kalıntı yöntemi geliştirmektir. Laboratuarda kullanıma uygunluğunu belirlemek için, yöntemin validasyonunun doğrusallık, tekrarlanabilirlik, tekrarüretilebilirlik, geri kazanım, LOQ ve LOD parametrelerine göre gerçekleştirilmesi amaçlanmaktadır.

\section{Materyal ve Metot}

\subsection{Kimyasallar}

Aseton içinde $1000 \mathrm{ng} / \mu \mathrm{L}$ 'lik klorpirifos metil, klorpirifos etil, metamidofos, simazin içeren pestisit standartları; Dr. Ehrenstorfer $\mathrm{GmbH}$ firmasından satın alındı. Aseton/hekzan içinde $1000 \mu \mathrm{g} / \mathrm{mL}$ 'lik olan diğer pestisit standartları (diazinon, etion, disülfoton, malatiyon, paratiyon metil, paratiyon etil) AccuStandard $\mathrm{M} 614$ 'den satın alınmış ve $-10^{\circ} \mathrm{C}^{\prime}$ de dondurucuda muhafaza edilmiştir. Gaz kromatografisine uygun üretilen diklorometan, aseton ve sodyum sülfat, Merck'ten temin edildi.

Asetonda çözünmüş ve herbiri $100 \mu \mathrm{g} / \mathrm{L}$ pestisit içeren stok çözeltilerden, 10 tane pestisiti ihtiva eden ve konsantrasyonları 2.5-25 $\mu \mathrm{g} / \mathrm{L}$ arasında değişen 4 farklı çözelti saf su içine ilave edilerek hazırlandı.

\subsection{Cihazlar}

Turbovap evaporator sistemi, ekstraksiyon işlemi gerçekleştikten sonra, buharlaştıma amacıyla kullanılmıştır.

Gaz kromatografi-kütle spektrometresi (GC/MS) çalışmaları için, Perkin Elmer marka kütle spektrometresi ile birleştirilmiş Perkin Elmer tipi Clarus 500 gaz kromatografi kullanılmıştır. Pestisitlerin ayrılması, 30m elit-5MS silika kılcal kolon (0.25mm i.d. ve 0.25 umfilm kalınlık) ile gerçekleştirildi. Pestisitler, kütle spektrometresi hem $2-1200 \mathrm{~m} / \mathrm{z}$ aralığında hem de zamanı önceden belirlenmiş seçilmiş iyon görüntüleme (SIR) ile tarandı. Geliştirilen yöntemle tüm pestisitlerin görüntülenmesi için, tüm moleküler iyon kütleleri belirlenerek Tablo 1'de verilmişstir. Ayrıca cihaz, standart bileşikler için binlerce kütle spektrumu kapsayan bir NIST kütüphanesi de içermektedir.

e-ISSN : 2148-2683 


\section{Avrupa Bilim ve Teknoloji Dergisi}

Tablo 1. Belirli pestisitler için kalma süresi ve kütle iyonları

\begin{tabular}{lll}
\hline & Alıkonma süresi & Kütle iyonu \\
\hline metamidofos & 6.12 & $47,94,95$ \\
simazin & 9.76 & $44,186,201$ \\
diazinon & 10.21 & $179,137,152$ \\
disülfoton & 10.46 & $88,89,29,97$ \\
klorpirifos metil & 11.23 & $286,125,288$ \\
paratiyon metil & 11.38 & $109,263,125,79$ \\
malatiyon & 12.44 & $125,173,93,127$ \\
klorpirifos etil & 12.51 & $97,197,199,29$ \\
paratiyon etil & 12.64 & $291,109,97,139$ \\
etion & 18.10 & $231,97,153,125$ \\
\hline
\end{tabular}

\subsection{Metotlar}

Sıvı-sıvı ekstraksiyonu için, organofosforlu bileşik içeren bir litre su numunesi alınarak 2 L'lik bir ayırma hunisine aktarıldı, karıştırıldı ve oda sıcaklığında dengeye gelmesi için bekletildi. Numuneler, üç kere 100 ml'lik diklorometan (DCM) ilave edilerek ekstrakte edildi. Ayırma hunisindeki aşırı basınç tahliye etmek için yaklaşık dört dakikada bir periyodik havalandırma yapılarak çalkalandı. Her diklorometan ilavesinde organik katmanın 10 dakika süreyle ayrılmasına izin verildi ve bu katmanlar bir erlende toplandı. Birleştirilen ekstrakt, bir susuz sodyum sülfat kolonu vasıtasıyla süzüldü ve $35^{\circ} \mathrm{C}^{\prime}$ ye ayarlanmış Turbovap evaporatör kullanılarak azot akımı altında kuruyana kadar buharlaştırıldı. Kalıntı, $1 \mathrm{ml}$ aseton ile çözündürüldü. 3 mikrolitrelik çözünmüş kalıntı split 50 modunda GC/MS içine enjekte edildi ve SIR modunda elde edilen kromatogramları Şekil 1'de verilmiştir. Taşıyıcı gaz olarak 1mL/dak'lık bir akış hızında \% 99.999 helyum kullanılmıştır. İlk enjektör sıcaklı̆̆g 60 oC'ye ayarlandı ve 0,5 dakika tutuldu. 999 oC/dk hızla 320 oC'ye çıkarıldı ve 10 dakika bekletildi ve 999 oC/dakika hızla sıcaklık azaltılarak 60 oC'ye düşürüldü. Numuneler, aşağıdaki sıcaklık programı kullanılarak analiz edilmişsir: başlangıç sıcaklı̆̆ $13^{\circ} \mathrm{C}$ 'de 1 dakika tutulmuştur, $20 \mathrm{oC} / \mathrm{dk}$ hızla $210^{\circ} \mathrm{C}$ ye arttırılmış ve 1 dakika bekletilmiştir, 2oC/dk ile 240 oC'ye yükseltilmiş ve 1 dakika bekletilmiştir ve son olarak 20oC/dk ile 280oC'ye yükseltilerek 5 dakika boyunca bekletilmiştir. Mass, tam tarama modunda (seçilen iyon görüntüleme modu) ve 29-300 kütle iyonu aralığında çalıştırıldı. İyonizasyon flamentinin emisyon akımı $70 \mathrm{eV}$ enerjiye ve $100 \mathrm{uA}$ üreten elektrona ayarlandı. 

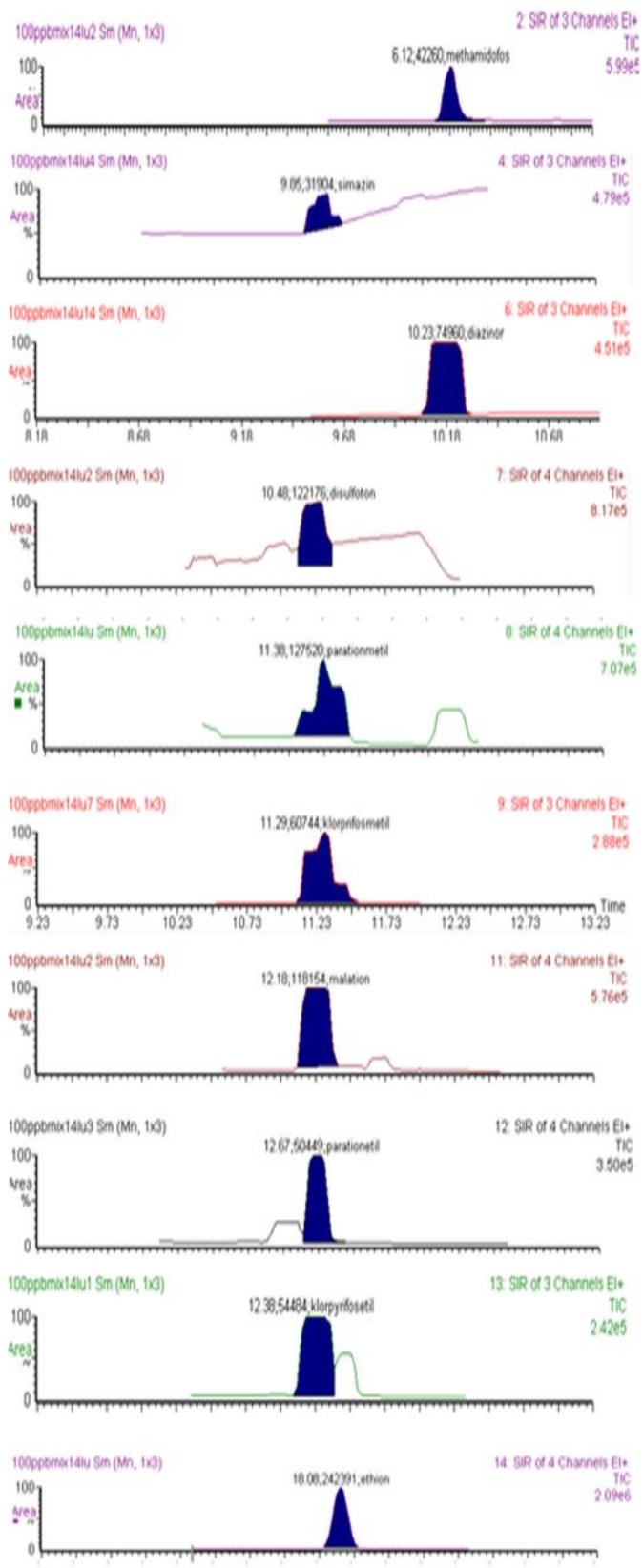

Şekil 1. GC/MS için SIR modu kullanılarak elde edilen kromatogramlar

\section{Araştırma Bulguları ve Tartışma}

Metodun performans özellikleri; standart çözeltiler, pestisit içermeyen numuneler ve pestisit enjekte edilen örnekler yardımıyla belirlenmiştir. Doğrulama çalışmaları, belli konsantrasyonlarda suya eklenen pestisitlerin ekstrakte edilmesi ile elde edilen örnekler yardımıyla gerçekleştirildi.

\subsection{Doğrusallık}

Kalibrasyon eğrileri, her bir pestisit için analit konsantrasyonuna karşı cihazın verdiği yanıtlar çizilerek hazırlandı. Kalibrasyon eğrileri on pestisit için 6 farklı kalibrasyon seviyesinde $(2.5,5,10,25,50$ ve $100 \mu \mathrm{g} / \mathrm{L})$ çizildi. Elde edilen korelasyon katsayıları Tablo 2'de verilmiştir. 
Tablo 2. Çalış1lan pestisitler için doğrusallıkta elde edilen korelasyon değerleri

\begin{tabular}{lcc}
\hline & $\begin{array}{c}\text { Alıkonma } \\
\text { süresi }\end{array}$ & $\begin{array}{c}\text { R(Korelasyon } \\
\text { katsayısi) }\end{array}$ \\
\hline Metamidofos & 6.12 & 0,998 \\
Simazin & 9.76 & 0,996 \\
Diazinon & 10.21 & 0,987 \\
Disulfoton & 10.46 & 0,986 \\
Klorpirifos metil & 11.23 & 0,990 \\
Paratiyon metil & 11.38 & 0,986 \\
Malation & 12.44 & 0,977 \\
Klorpirifos etil & 12.51 & 0,992 \\
Paratiyon etil & 12.64 & 0,987 \\
Etion & 18.10 & 0,973 \\
\hline
\end{tabular}

\subsection{Doğruluk}

Doğruluk "Gerçeklik" (Geri kazanım) ve "Kesinlik" (tekrarlanabilirlik ve tekrarüretilebilirlik) olarak iki bileşenle ifade edilir:

Tekrarlanabilirlik çalışması için tek konsantrasyonda $(10 \mu \mathrm{g} / \mathrm{L})$ ve aynı günde altı analiz $(6 \times 2=12)$ yapılmıştır ve sonuçlar tablo 3'de verilmiştir.

Tablo 3. Tekrarlanabilirlik; $10 \mu \mathrm{g} / \mathrm{L}$ 'de analiz edilen pestisitlerin ortalama, SD, RSD, $r$ değerleri

\begin{tabular}{lcccccc}
\hline & $\begin{array}{c}\text { Tekrar } \\
\text { Sayıs }\end{array}$ & Ortalama & SD & RSD & \%RSD & r \\
\hline \multirow{2}{*}{ metamidofos } & 1 & 9.55 & 0.98 & 0.10 & 10.32 & 2.79 \\
simazin & 2 & 9.29 & 0.94 & 0.10 & 10.14 & 2.67 \\
diazinon & 1 & 8.63 & 1.94 & 0.22 & 22.44 & 5.48 \\
& 2 & 8.67 & 1.86 & 0.21 & 21.43 & 5.26 \\
disulfoton & 1 & 10.48 & 0.68 & 0.06 & 6.48 & 1.92 \\
& 2 & 10.44 & 0.94 & 0.09 & 9.01 & 2.66 \\
klorpirifos metil & 1 & 11.49 & 0.44 & 0.03 & 3.81 & 1.24 \\
& 2 & 11.46 & 0.84 & 0.07 & 7.34 & 2.38 \\
paratiyon metil & 1 & 12.08 & 1.43 & 0.11 & 11.88 & 4.06 \\
\multirow{3}{*}{ malation } & 1 & 12.19 & 1.44 & 0.11 & 11.80 & 4.07 \\
\multirow{3}{*}{ klorpirifos etil } & 2 & 9.56 & 0.84 & 0.08 & 8.76 & 2.37 \\
& 1 & 9.27 & 1.34 & 0.14 & 14.40 & 3.78 \\
paratiyon etil & 2 & 9.49 & 0.49 & 0.05 & 5.12 & 1.38 \\
etion & 1 & 9.64 & 1.08 & 0.11 & 11.49 & 3.06 \\
& 2 & 9.73 & 1.34 & 0.13 & 13.75 & 3.78 \\
& 1 & 10.05 & 0.80 & 0.08 & 8.01 & 2.28 \\
& 2 & 9.88 & 0.41 & 0.04 & 4.13 & 1.16 \\
& 1 & 10.64 & 1.12 & 0.10 & 10.52 & 3.17 \\
& 2 & 10.76 & 1.36 & 0.12 & 12.61 & 3.84 \\
\hline
\end{tabular}

Tekrarüretilebilirlik için; $25 \mu \mathrm{g} / \mathrm{L}$ konsantrasyona sahip dokuz $(9 \times 2=18)$ farklı örneğin analizleri, 3 farklı günde gerçekleştirildi (Tablo 4). 
European Journal of Science and Technology

Tablo 4. Tekrarüretilebilirlik; $25 \mu \mathrm{g} / \mathrm{L}$ konsantrasyonuna sahip (yalnızca klorpirifos metil için $100 \mu \mathrm{g} / \mathrm{L}$ ) pestisitlerin ortalama, SD, RSD, RSDr değerleri

\begin{tabular}{|c|c|c|c|c|c|c|c|c|c|}
\hline & $\begin{array}{c}\text { Tekrar } \\
\text { Sayısı }\end{array}$ & Ortalama & SD & RSD & $\%$ RSD & {$\left[\left(a_{i}-b_{i}\right) / \bar{x}_{l}\right]^{2}$} & RSDr & $\%$ RSDr & $\mathbf{R}$ \\
\hline \multirow{2}{*}{ metamidofos } & $\mathrm{a}$ & 26.16 & 4.16 & 0.15 & 15.91 & \multirow{2}{*}{0.54} & \multirow{2}{*}{0.17} & \multirow{2}{*}{17.32} & 11.66 \\
\hline & $\mathrm{b}$ & 23.91 & 4.00 & 0.16 & 16.74 & & & & 11.20 \\
\hline \multirow{2}{*}{ simazin } & $\mathrm{a}$ & 23.94 & 2.11 & 0.08 & 8.83 & \multirow{2}{*}{0.31} & \multirow{2}{*}{0.13} & \multirow{2}{*}{13.01} & 5.92 \\
\hline & $\mathrm{b}$ & 22.56 & 2.98 & 0.13 & 13.23 & & & & 8.35 \\
\hline \multirow{2}{*}{ diazinon } & $\mathrm{a}$ & 23.15 & 2.18 & 0.09 & 9.41 & \multirow{2}{*}{0.42} & \multirow{2}{*}{0.15} & \multirow{2}{*}{15.24} & 6.09 \\
\hline & $\mathrm{b}$ & 25.20 & 4.59 & 0.18 & 18.21 & & & & 12.85 \\
\hline \multirow{2}{*}{ disulfoton } & $\mathrm{a}$ & 25.12 & 2.02 & 0.08 & 8.03 & \multirow{2}{*}{0.13} & \multirow{2}{*}{0.08} & \multirow{2}{*}{8.51} & 5.65 \\
\hline & $\mathrm{b}$ & 24.48 & 1.78 & 0.07 & 7.28 & & & & 4.98 \\
\hline \multirow{2}{*}{ klorpirifos metil } & $\mathrm{a}$ & 97.04 & 5.33 & 0.05 & 5.49 & \multirow{2}{*}{0.06} & \multirow{2}{*}{0.06} & \multirow{2}{*}{5.81} & 14.91 \\
\hline & $\mathrm{b}$ & 99.52 & 4.93 & 0.04 & 4.95 & & & & 13.79 \\
\hline \multirow{2}{*}{ paratiyon metil } & $\mathrm{a}$ & 25.37 & 3.12 & 0.12 & 12.28 & \multirow{2}{*}{0.15} & \multirow{2}{*}{0.09} & \multirow{2}{*}{9.26} & 8.72 \\
\hline & $\mathrm{b}$ & 24.27 & 3.09 & 0.12 & 12.73 & & & & 8.65 \\
\hline \multirow{2}{*}{ malation } & $\mathrm{a}$ & 24.39 & 1.87 & 0.07 & 7.68 & \multirow{2}{*}{0.09} & \multirow{2}{*}{0.07} & \multirow{2}{*}{7.36} & 5.25 \\
\hline & $\mathrm{b}$ & 26.03 & 1.22 & 0.04 & 4.67 & & & & 3.40 \\
\hline \multirow{2}{*}{ klorpirifos etil } & $\mathrm{a}$ & 27.62 & 2.96 & 0.10 & 10.73 & \multirow{2}{*}{0.46} & \multirow{2}{*}{0.16} & \multirow{2}{*}{16.05} & 8.29 \\
\hline & $\mathrm{b}$ & 24.99 & 3.48 & 0.13 & 13.95 & & & & 9.76 \\
\hline \multirow{2}{*}{ paratiyon etil } & $\mathrm{a}$ & 24.99 & 3.63 & 0.14 & 14.54 & \multirow{2}{*}{0.18} & 10 & 1002 & 10.17 \\
\hline & $\mathrm{b}$ & 24.15 & 3.39 & 0.14 & 14.07 & & 0.10 & 10.02 & 9.52 \\
\hline 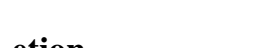 & $\mathrm{a}$ & 23.75 & 3.58 & 0.15 & 15.09 & 0 & 5 & 1511 & 10.03 \\
\hline etion & $\mathrm{b}$ & 25.30 & 3.69 & 0.14 & 14.57 & 0.41 & 0.15 & 15.11 & 10.32 \\
\hline
\end{tabular}

Tekrar üretilebilirlik relatif standart sapma (RSDr), Tekrarüretilebilirlik (R) ve Tekrarlanabilirlik (r) aşağıdaki formüller yardımıyla hesaplanmıştır.

$\mathbf{R S D}_{\mathbf{r}}=\sqrt{\frac{\sum\left[\left(\mathbf{a}_{\mathbf{i}}-\mathbf{b}_{\mathbf{i}}\right) / \overline{\mathbf{x}_{\mathbf{1}}}\right]^{2}}{2 \mathbf{n}}}$

$\mathrm{r}=$ Standard Deviation $(\mathrm{SD}) * 2.83$

$\mathrm{R}=\mathrm{SD} * 2.8$

Gerçeklik, iki konsantrasyon seviyesi için suya eklenen 10 tane pestisitin geri kazanım yüzdesi ile belirlenmiştir ve sudaki pestisit kalıntıları için, ortalama \%geri kazanım, standart sapma(SD) ve relatif standart sapma(RSD\%) Tablo 5'de verilmiştir.

Tablo 5. İki farklı konsantrasyon seviyesinde zenginleştirilmiş numuneler için ortalama geri kazanımlar, SD ve RSD değerleri

\begin{tabular}{lccccc}
\hline & $\begin{array}{c}\text { Konsantras- } \\
\text { yon } \\
(\boldsymbol{\mu g} / \mathbf{L})\end{array}$ & $\begin{array}{c}\text { Ortalama } \\
\text { geri } \\
\text { kazanım } \\
(\boldsymbol{\%})\end{array}$ & SD & RSD & $\begin{array}{c}\text { RSD } \\
(\%)\end{array}$ \\
\hline metamidofos & 2.5 & 96.80 & 7.07 & 0.07 & 7.31 \\
simazin & 50 & 99.28 & 2.62 & 0.02 & 2.64 \\
& 2.5 & 102.33 & 9.48 & 0.09 & 9.27 \\
diazinon & 50 & 100.28 & 4.03 & 0.04 & 4.02 \\
& 2.5 & 113.07 & 9.55 & 0.08 & 8.45 \\
disülfoton & 50 & 96.53 & 6.64 & 0.06 & 6.88 \\
& 2.5 & 102.47 & 7.09 & 0.06 & 6.93 \\
Klorpirifos & 50 & 97.24 & 4.48 & 0.04 & 4.61 \\
metil & 2.5 & 92.60 & 5.68 & 0.06 & 6.14 \\
paratiyon metil & 50 & 97.06 & 7.38 & 0.07 & 7.60 \\
& 2.5 & 106.27 & 12.0 & 0.11 & 11.3
\end{tabular}




\begin{tabular}{lccccc}
\multicolumn{5}{c}{ Avrupa Bilim ve Teknoloji Dergisi } \\
& 50 & 100.25 & 4.67 & 0.04 & 4.66 \\
\multirow{4}{*}{ malatiyon } & 2.5 & 94.13 & 13.9 & 0.14 & 14.8 \\
\multirow{4}{*}{ klorpirifos etil } & 50 & 101.48 & 2.80 & 0.02 & 2.76 \\
& 2.5 & 100.33 & 2.77 & 0.02 & 2.76 \\
\multirow{4}{*}{ paratiyon etil } & 50 & 99.69 & 6.61 & 0.06 & 6.63 \\
& 2.5 & 99.07 & 6.09 & 0.06 & 6.15 \\
\multirow{4}{*}{ etion } & 50 & 99.54 & 13.0 & 0.13 & 13.1 \\
& 2.5 & 97.20 & 3.43 & 0.03 & 3.53 \\
\hline & 50 & 97.51 & 4.79 & 0.04 & 4.91 \\
\hline
\end{tabular}

\subsection{Nicel tayin sınırı (LOQ) ve belirtme alt sınırı (LOD)}

$5 \mu \mathrm{g} /$ Lkonsantrasyona sahip her bir pestisitin standart sapmaları belirlenerek LOD ve LOQ değerleri belirlenmiştir. LOD ve LOQ değerleri sırasıly standart sapmanın 3 ve 10 katı kullanılarak elde edildi.

Tablo 6. LOD, LOQ, Mean, SD, RSD values at $5 \mu \mathrm{g} / \mathrm{L}$ for GC/MS.

\begin{tabular}{lcccccc}
\hline & Ortalama & SD & RSD & \%RSD & LOD & LOQ \\
\hline Metamidofos & 5.26 & 0.81 & 0.15 & 15.37 & 2.42 & 8.08 \\
Simazin & 5.03 & 0.90 & 0.18 & 17.89 & 2.69 & 8.99 \\
Diazinon & 5.33 & 0.73 & 0.14 & 13.65 & 2.19 & 7.28 \\
Disulfoton & 5.82 & 1.06 & 0.18 & 18.14 & 3.17 & 10.55 \\
Klorpirifos metil & 5.69 & 1.42 & 0.25 & 24.85 & 4.24 & 14.15 \\
Paratiyon metil & 5.44 & 0.63 & 0.12 & 11.62 & 1.89 & 6.32 \\
Malation & 5.46 & 0.65 & 0.12 & 11.85 & 1.94 & 6.47 \\
Klorpirifos etil & 5.00 & 0.42 & 0.08 & 8.46 & 1.27 & 4.23 \\
Paratiyon etil & 5.12 & 0.84 & 0.16 & 16.31 & 2.50 & 8.35 \\
Etion & 5.19 & 0.43 & 0.08 & 8.28 & 1.29 & 4.29 \\
\hline
\end{tabular}

\section{Sonuç}

Doğrusallık sonuçlarına göre, korelasyon katsayılarının (R) büyük çoğunluğu 0,973 'e eşit veya daha yüksek bulunmuştur(Tablo 2). RSD\%, tekrarlanabilirlik için \%5'den küçük ve tekrarüretilebilirlik için \% 12 den küçük bulunmuștur. (Tablo 3 ve 4 ). Test edilen pestisitlerin çoğunun geri kazanım değerleri, yüksek konsantrasyonlarda çalışıldığında \% 96, düşük konsantrasyonlarda çalışıldığında \%92'nin üzerinde elde edilmiştir. Ortalama geri kazanımların hiçbiri \% 106'yı geçmemiştir. Uluslararası yönergeler, kantitatif metodların validasyonunda ortalama geri kazanımının \%70-110 aralığında olması gerektiğini göstermektedir (Commission, 2013). Sonuçların bu yönergelere uygun olduğu görülmüştür. Yüksek geri kazanımlar, $50 \mu \mathrm{g} / \mathrm{L}$ 'lık en yüksek konsantrasyon seviyesinde gözlenmiştir. Geri kazanımlardaki değiş̧enlik LOQ'ya yakın konsantrasyonlara yaklaştıkça daha yüksek olmaktadır. LOD ve LOQ değerleri sırasıyla $1.269 \mu \mathrm{g} / \mathrm{L}$ ila $4.244 \mu \mathrm{g} / \mathrm{L}$ ve $4.231 \mu \mathrm{g} / \mathrm{L}$ ila $14.145 \mu \mathrm{g} / \mathrm{L}$ arasında değişmektedir (Tablo 6).

Bu çalışmada, su numunelerinde tek bir enjeksiyonla 10 pestisit kalıntısının analizi için yeni ve çoklu kalıntı yöntemi geliştirildi. GC/MS ile analiz, yaklaşık 18 dakikada gerçekleştirildi. Altı hücreye sahip Turbowap evaporatör sistemi ile aynı anda 6 numunenin uçurulması sağlanarak analizin toplam süresi azaltıldı. Bu durum yüksek numune sayısının olduğu rutin analizlerde gereklidir. Geliştirilen yöntem yüksek numune sayısı için elverişlidir ve düşük maliyete sahiptir. 


\section{Teşekkür}

Yazar, Erzurum Halk Sağlığı Kurumu'na, yardımlarından dolayı teşekkürlerini sunar.

\section{Kaynaklar}

Beltran, J., Lopez, F. J., Cepria, O.,Hernandez, F. 1998. Solid-phase microextraction for quantitative analysis of organophosphorus pesticides in environmental water samples. Journal of Chromatography A, 808(1-2), 257-263.

Castilho, J. A. A., Fenzl, N., Guillen, S. M.,Nascimento, F. S. 2000. Organochlorine and organophosphorus pesticide residues in the Atoya river basin, Chinandega, Nicaragua. Environmental Pollution, 110(3), 523-533.

Commission, E. (2013). Method validation and quality control procedures for pesticides residues analysis in food and feed. (Type No. Report Number).

Costa, L. L., Sant ana, E. S., Suchara, E. A., Benato, V. S.,Carasek, E. 2008. Determinação de herbicidas usados no cultivo de arroz irrigado na região sul do estado de Santa Catarina através da SPME-GC-ECD. Química Nova, 31(1), 79.

de Souza Pinheiro, A.,de Andrade, J. B. 2009. Development, validation and application of a SDME/GC-FID methodology for the multiresidue determination of organophosphate and pyrethroid pesticides in water. Talanta, 79(5), 1354-1359.

Domotorova, M.,Matisova, E. 2008. Fast gas chromatography for pesticide residues analysis. Journal of Chromatography A, 1207(12), 1-16.

Dorea, H. S., Tadeo, J. L.,SanchezBrunete, C. 1996. Determination of organophosphorus pesticide residues in fruits by gas chromotography with ITD and NPD detection. Chromatographia, 43(7-8), 380-386.

Driss, M., Hennion, M.-C.,Bouguerraca, M. 1993. Determination of carbaryl and some organophosphorus pesticides in drinking water using on-line liquid chromatographic preconcentration techniques. Journal of Chromatography A, 639(2), 352-358.

Jin, B. H., Xie, L. Q., Guo, Y. F.,Pang, G. F. 2012. Multi-residue detection of pesticides in juice and fruit wine: A review of extraction and detection methods. Food Research International, 46(1), 399-409.

Komatsu, E.,Vaz, J. M. 2004. Otimização dos parâmetros de extração para determinação multiresíduo de pesticidas em amostras de água empregando microextração em fase sólida. Química Nova, 27(5), 720-724.

Menezes Filho, A., dos Santos, F. N.,Pereira, P. A. d. P. 2010. Development, validation and application of a method based on DISPME and GC-MS for determination of pesticides of different chemical groups in surface and groundwater samples. Microchemical Journal, 96(1), 139-145.

Park, J. H., Iqbal Rouf Mamun, M., Abd El-Aty, A., Na, T. W., Choi, J. H., Ghafar, M., Kim, K. S., Kim, S. D.,Shim, J. H. 2011. Development and validation of a multiresidue method for determination of 37 pesticides in soil using GC-NPD. Biomedical Chromatography, 25(9), 1003-1009.

Piedra, L., Tejedor, A., Hernando, M. D., Aguera, A., Barcelo, D.,Fernandez-Alba, A. 2000. Screening of antifouling pesticides in sea water samples at low ppt levels by GC-MS and LC-MS. Chromatographia, 52(9-10), 631-638.

Rocha, M. J., Ribeiro, M. F., Cruzeiro, C., Figueiredo, F.,Rocha, E. 2012. Development and validation of a GC-MS method for determination of 39 common pesticides in estuarine water-targeting hazardous amounts in the Douro River estuary. International Journal of Environmental Analytical Chemistry, 92(14), 1587-1608.

Suman, P.,Singh, D. K. 2011. Estimating the uncertainty of pesticide residue analysis from mango using multi-residue analysis and validation of method. Toxicological and Environmental Chemistry, 93(10), 1880-1896.

Vidal, J. L. M., Liebanas, F. J. A., Rodriguez, M. J. G., Frenich, A. G.,Moreno, J. L. F. 2006. Validation of a gas chromatography/triple quadrupole mass spectrometry based method for the quantification of pesticides in food commodities. Rapid Communications in Mass Spectrometry, 20(3), 365-375. 